DOI: $10.22559 /$ folklor.942

Folklor/edebiyat, cilt:25, sayı: 97-1, 2019/1

\title{
Denetmen Görev ve Sorumlukları; Kıbrıs Örneği
}

\section{Duties and Resposibilities of Education Supervisors; A case of Cyprus}

\section{Osman Vaiz*}

Nesrin M. Bahçelerli **

Akış Yeşilada ***

\begin{abstract}
$\ddot{O} \mathbf{z}$
Denetim, yönetim süreçlerinden biridir ve bu sebepten eğitim yönetimi de eğitim denetiminden ayrı düşünülmemektedir. İlgili kuruma, daha iyi duruma gelmesi için hizmet eden denetim, yönetimin bir alt sistemi, kamu yönetimi içinde bir devlet görevi ve yönetici yeterlilikleri açısından bir uzmanlık alanı ve sorumluluğudur. Araştırmanın amacı; Kıbrıs'ta bulunan iki toplumun eğitim denetmen görev sorumluluklarında ki benzerlik ve farklılıkları ortaya çıkarmaktır. Araştırmada, literatür gözden geçirilerek çeşitli araştırmacıların ve kurumların denetmen kavramı, özellikle de ilköğretim kurumlarında denetmenlerin görev ve sorumluluklarını ortaya çıkarma amaçlanmaktadır. Araştırma literatür taramasına dayalı olup, iki toplumdaki yasa ve uygulamaları irdelemektedir. Araştırma sonucunda iki toplum yasa ve uygulamalarında farklılıklar olduğu görülmektedir. Denetmen atama ve yetki süreci belirgin farklıklar ortaya çıkmaktadır.
\end{abstract}

Anahtar sözcükler: denetmen, sorumluluk, Kıbrls, Kuzey Kıbrıs, Güney Kıbrıs

\begin{abstract}
The supervisor is one of the management processes, and education management is not considered separately from the educational supervision. It is an area of expertise and responsibility in terms of auditing, a sub-system of management, a state duty in public administration, and managerial competencies that serve the relevant institution to make it better. The aim of the research; the two communities in Cyprus are to reveal the similarities and differences in the responsibilities of the educational supervisor. In the research, the concept of supervisor of various researchers and institutions is aimed to reveal the duties and responsibilities of supervisors especially in primary education institutions. The research is based on literature review and examines laws and practices in two communities. As a result of the research, it is seen that the two communities differ in their laws and
\end{abstract}

\footnotetext{
* Dr., Uluslarası Kıbrıs Üniversitesi, Eğitim Bilimleri Fakültesi

** Doç.Dr., Yakın Doğu Üniversitesi, Turizm ve Otel İşletmeciliği Yüksekokulu

${ }^{* * *}$ Uzman
} 
practices. There are significant differences in the appointment of supervisors and the process of authorization.

Keywords: supervisor, responsibilities, Cyprus, North Cyprus, South Cyprus

\section{Giriş}

Denetim, örgüt içindeki faaliyetlerin belirlenen amaç ve hedefler doğrultusunda belirli ilke ve kurallara uygunluğunun ortaya konulduğu ve değerlendirildiği süreçtir. Dolayısıyla Öyle ki örgütün varlığını sürdürmesi ve ilerlemesi için denetim vazgeçilmezdir. Eğitim yönetimi ve denetimin etkinliklerinin içeriği, sistemi oluşturan tüm kurum ve çalışanların belirlenen amaç ve hedefler doğrultusunda yasalar çerçevesinde davranıp davranmadığını belirleyerek, gereken inceleme ve soruşturmaların yapılması, aynı zamanda eğitim etkinliklerini değerlendirme ve geliştirme sürecine rehberlik etmeyi kapsamaktadır (Aydin,2007).

Eğitim yönetimi süreçlerinden biri olan denetim, yöneticinin yapması gereken işlerden birisidir (Başar, 2006). Ancak, her biri uzmanlık gerektiren bu işlerin, yönetici tarafından yapılmasının güçlüğü nedeniyle, müfettişlerce yapılmasını gerekli kılınmıştır (Gündüz ve Balyer, 2012). Bir sistemin etkili biçimde işleyişi için belirli faktörler önem taşımaktadır. Bunlar, öncelikli olarak belirlenen amaçlar doğrultusunda çalışma sürecinin değerlendirilmesi, alt sistemler arasında birleşme ve koordineli çalışmanın sağlanması, tüm alt sisteme hedeflenen amaçlar doğrultusunda, bütünlük içinde rehberlik yapılması ve denetimlerin etkili sürdürülmesidir.

Denetimin amaçları kalite kontrol, profesyonel gelişme ve öğretmen motivasyonu olmak üzere üç kategoride açıklanmıştır (Sergiovanni ve Starrat, 2002). Eğitim ve öğretimde kalite kontrol, kontrol etme; geliştirme; profesyonelleşme; öğretmenin meslekte gelişimini sağlayarak öğretme sürecini daha etkili sürdürmelerini, öğretim becerilerini geliştirerek öğretim teknik ve bilgilerini geliştirme; öğretmen motivasyonu, öğretme istek ve heyecanını öu amaçlar arasında açıklanmaktadır (Terzi, 1996).

Her kurumun denetmen seçimi, yetiştirme yöntemleri ve görevlendirme biçimlerinde farklılıklar olsa da genellikle denetmenlerin, denetim yapılacak alanda eğitim vermiş, bunun yanında denetimin gerekli gördügü bilgi ve becerilere sahi olması gerekli görülmektedir. Denetmenler, denetim sürecinde örgütün üst düzey yöneticilerini çalışmaları hakkında bilgi 
aktarmaktadırlar dolaysıyla gerçekleri arama, bulma ve bunları olduğu gibi aktarma zorunluluğu bulunmaktadır. Denetmenlerin bağımsız çalışmaları, çekinmemeleri ve cesaret ile görevlerini yapmaları gerekmektedir (Taymaz, 2011).

Araştırma, Kıbrıs’ta bulunan iki toplumun eğitim denetmen görev sorumluluklarında ki benzerlik ve farklılıkları ortaya çıkarmayı amaçlamaktadır.

\section{Yöntem}

Araştırmada döküman analizi modeli, eğitim denetimi ile ilgili çalışmalarının içerik analizi bakımından değerlendirilmesine yönelik, tarama modeli uygulanmıştır.

Döküman analizi, araştırma konusu kapsamında bilgi içeren yazılı materyal ve dökümanların incelenmesini kapsayan, mevcut bulunan belge ve kayıtların veri kaynağını oluşturduğu, sistemli araştırma yöntemidir. Döküman analizinin başarılı olabilmesi için öncelikli olarak konuyla bağlantılı belgelere ulaşmak, incelemek ve durumu ortaya çıkaracak bir senteze varmak için gerekli düzenlemenin yapılmasıdır (Karasar, 2007, Yıldırım ve Şimşek, 2006). Döküman analizi kapsamında aşağıda belirtilen adımlar izlenmişitir;

1. Uluslararası ve ulusal veri tabanalarında ilgili makalelerin taranıp, incelenmesi

2. YOK ulusal tez merkezinden yapılan tarama sonucu konu ile ilgili tezlerin incelenmesi

3. Kuzey ve Güney Kıbırs yasa ve tüzüklerinin incelenmesi

4. Araştırmacıların tarafından belirlenen temalar doğrultusunda değerlendirmelerin yapılmasi

5. Elde edilen verilerin betimsel analiz yöntemi ile incelenmesi

Öncelikli olarak araştırmada ilgili literatür taranmış, ulusal düzeyde yasa ve tüzüklerin yanı sıra uluslararası düzeyde yazılı ve basılı kaynaklar taranmıştır. Elde edilen veriler kaynak gösterilerek belirtilmiştir.

\section{Bulgular}

Kuzey ve güney kıbrıs denetmenlerin görev yetki ve sorumlulukları 
KKTC'de eğitim sisteminde denetmenlerinin sorumluluk, görev ve yetkileri aşağıdaki belirtildiği gibidir; 1. Eğitim Baş denetmeninin sorumluluğunda ve gözetiminde yürütülen denetim süreçleri kapsamında değerlendirilen, araştırılan ve incelenen çalışmalarının sonucunda denetim sürecinde ortaya çıkan eksikler, aksayan, yetersiz kalan ve uygunsuz durumları sorumlu olan Eğitim Baş denetmeni tarafından Üst Kurul Başkanlığına rapor edilmektedir; 2. Eğitim denetim ve değerlendirme sürecinde bulunan ders, hem öğretmenlere hem de kuruma dikkat edilecek ilke ve ölçütler çerçevesinde rehberlik etmektedir ve bunun yanı sıra yönlendirir ve iş ortamında yetişmelerine olanak sağlar;.3. Eğitim Denetleme Kurulu Başkanı, Başkan Yardımcısı veya sorumlu Eğitim Baş denetmenleri tarafından verilen mevkiine uygun diğer görev ve sorumlulukları da yerine getirmektedir; 4. Denetmen Üst Kurul Başkanı, Başkan Yardımcısına ve ilgili Eğitim Baş denetmene karşı görev ve sorumluluklarını etkili ve verimli biçimde yerine getirmekten sorumludur; 5. İlgili amirleri aracılığıyla verilen ve mevkiine uygun diğer görevleri de yerine getirmekten sorumludur; 6 . Üst Kurul tarafından uygun görüldüğü takdirde öğretmenlere yön verme, rehberlik etme, iş ortamında eğitme ve değerlendirme amacıyla, Üst Kurulun öngördüğü gerçek veya tüzel kişiler ya da Kuzey Kıbrıs Türk Cumhuriyeti veya dışındaki üniversitelerde görev alan öğretim elemanları eğitim denetmenlerine teknik yardım ve destek sağlayabilmektedir.

\section{Yasa ve tüzükler}

Kuzey Kıbrıs'ta eğitim denetimi görevini, 17 Nisan 2006 tarihli yasa uyarınca "Milli Eğitim Denetleme, Değerlendirme ve Yönlendirme Kurulu” yerine getirmektedir. Kurulun yapısı aşağıdaki gibidir. KKTC'de denetleme işi ile görevli olan kurulun yapısında bir başkan, bir başkan yardımcısı, 8/01/2009 tarihi itibarıyla 4 Baş denetmen, 19 ilköğretim denetmeni, 13 orta eğitim denetmeni ve 2 sekreter bulunmaktadır (MEDDYK, 2008). KKTC'de eğitim denetleme ve değerlendirme organları kendi içinde dört kurula ayrılmıştır.

Bunlar (MEDDYK yasas1, 2006):

i. Üst Kurul - Eğitim Denetleme, Değerlendirme ve Yönlendirme Üst Kurulu: Başkan, müdür muavini (başkan yardımcısı), Eğitim baş denetmeni ve genel kurul üyeleri tarafından seçilen beş eğitim denetmeni oluşturmaktadır.

ii. Genel Kurul - Eğitim Denetmeni Genel Kurulu: Eğitim denetleme ve değerlendirme sürecini kapsayan konularda danışma görevi görmektedir. Kurulu üst kurul başkan ve başkan yardımcısının yanı sıra eğitim baş denetmeni ve diğer eğitim denetmenlerinden oluşmaktadır. 
iii. İlçe Kurulu - İlçe Eğitim Denetleme, Değerlendirme ve Yönlendirme Kurulu: Kurul, Bakanlık aracılığıyla yetkilendirilen ilçe okulları, okul aile birlikleri, eğitim baş denetmeni eğitim denetmenlerinden oluşmaktadır.

iv. Okul Kurul - Okul Eğitim Denetleme, Değerlendirme ve Yönlendirme Kurulu: Okul kurulu, okul müdürü başkanlığında okulların kendi bünyelerinde oluşturdukları kuruldur. Kurulun diğer üyeleri, müdür muavinleri, bölüm şefleri, okul aile birliği temsilcileri, atölye şefleri ve ilgili öğretmen sendikaları ile öğrenci temsilcileridir.

2005 yılından önce hem ilköğretim sendikası olan Kıbrıs Türk Öğretmenler Sendikası hem de Kıbrıs Türk Orta Öğretim Sendikası okul yöneticiliğinin ve denetmenliğin ayrı birer meslek olduğuna vurgu yaparak; okul yöneticiliği ve denetmenliğe atanacak öğretmenlerde bu alanlarda eğitilmelerinin gerektiğini savunmuşlardır.

Eğitim yönetimi Güney Kıbrıs’ta merkezi yapı ile yürütülmektedir. Bakanlar Kurulu eğitim politikalarının oluşturulmasında en üst düzey birimdir. Eğitim ve Kültür Bakanlığı tüm eğitim ve öğretim sürecinden sorumludur (Eurydice/Cedefob, 2003b; Eurydice/ Eurybase, 2002). Ulusal olarak irdelendiğinde bakanlık eğitim yasalarının oluşturulması ve eğitimin yönetilmesi hususlarında sorumlu birimdir ancak eğitim yönetimi ve yasalarının hazırlanma sürecinde hukuk birimi ile işbirliği yapmaktadır. Eğitimin politik lideri olan bakan, Cumhurbaşkanı tarafından atanmaktadır. Kadrolu çalışan olan Genel Müdür, bakana danışmanlık yapmaktadır. Aynı zamanda Genel müdür, yönetim ve finans konularından da sorumludur (Eurydice/ Eurybase, 2002). Oluşturulan Eğitim Hizmeti Komisyonu ise ilgili öğretmenlerin atanmaları, yer değiştirmeleri, başka bir kurumda görevlendirilmeleri, terfi ettirilmeleri ve denetimlerinden sorumludurlar (Eurydice/Cedefob, 2003; Eurydice/Eurybase, 2002). Bölgesel olarak irdelendiğinde, Kıbrıs altı bölgeye ayrılmaktadır. Altı bölgenin dördünde birer eğitimden sorumlu bölge müfettişi bulunmaktadır. Sorumlu oldukları kuruma göre müfettişlerin ikamet yerleri değişiklik göstermektedir. Müfettiş, ilköğretim kurumundan sorumlu ise sorumlu olunan bölgede, ortaöğretimden sorumlu ise merkezde ikamet etmektedirler. Teknik ve mesleki eğitim veren kurum sayısı az olduğundan bölge müfettişi atanmamaktadır (Eurydice, 2007). Yerel düzeyde ise; okulların beş ile on bir kişi arasında değişen kendi kurlları vardır. Bu kurullar beş yılda bir seçilmektedir. Okul yönetiminde birinci derce yetkili olan bu kurul, ilk ve orta öğretim kurumlarından sorumlu olmaktadır. Başlıca görevleri arasında okula ait bina, arsa, teknolojik donanım vb. konularını kapsamaktadır (Eurydice/Eurybase, 2002). 
Müdür, müdür yardımcısı ve kıdemli öğretmenler okulöncesi ve ilköğretim kurumlarının yönetilmesinden sorumludurlar. Öğretmen kurulu, okul içerisinde en üst düzey yetkili kurumdur. Okul öncesinin büyüklüğü göz önünde bulundurularak kurumdan sorumlu bir müdür veya kıdemli öğretmen bulunmaktadır. İlköğretim kurumlarında ise müdürün yanı sıra büyüklüğe göre bir veya daha fazla müdür muavini bulunmaktadır. Okulöncesi veya ilköğretim kurumlarında müdür yardımcı olabilmek için öğretmenin en az 13 yıl eğitim tecrübesi ve en az beş yıl devlet okulunda görev almaları gerekmektedir. Ortaöğretim kurumlarının yönetim yapısı incelendiğinde, müdür, müdür yardımcısı ve çalışan dernek ve sendikaları eğitim ve öğretimin yürütülmesinden sorumludur. Aynı zamanda öğrenci konseylerinin yönetim sürecine katılması teşvik edilmektedir. Öğrenci konseyi, sınıf başkanları ve 5 üyeden oluşmaktadır (Eurydice, 2007).

Eğitim, merkezi olarak yönetilmektedir. Bakanlar kurulu, en üst düzey eğitim politikalarının geliştirilmesi ve oluşturulmasından sorumludur. Teftiş kurulunun sorumluluğu ise ortaöğretim, ilköğretim ve okul öncesi kademelerinde ki okulların gözetimidir. Öte yandan müfredatın geliştirilmesi ve kamuya ait eğitim politikalarının belirlenmesinin yanı sıra öğretmenlerin ödüllendirilmesi de Teftiş Kurulu'nun sorumluluğundadır. Öğretimin her evresinde Teftiş Kurulu yer almaktadır. Müfettişlerin birçoğu, ilköğretim ve okul öncesi kademelerinde tüm derslerin denetlenmesinden sorumludurlar. Ancak, Sanat, Beden Eğitimi ve benzeri özel alan dersleri için alan müfettişleri sorumludur. Eğitim kanunu gereği, ortaöğretim kademesinde yer alan özel alan derslerinden sorumlu müfettişler, öğretmenin mesleki gelişimini ve performansını arttırmasına yönelik danışmanlık ve rehberlik etmektedirler. Bilgilendirme yıl boyunca en az iki defa düzenlenen seminer ile yapılmaktadır. Tablo 1'de Güney Kıbrıs'ta denetmen ve baş denetmenin görev ve yetkileri özetlenmiştir.

Tablo 1. Güney Kıbrıs’ta Denetmenlerin Görev ve Yetkileri

\section{İlköğretimde}

Görev ve Yetkileri

\section{Tartışma}

Eğitim sistemi her ülkenin gelişimi ve geleceği için büyük önem taşımaktadır. Bu nedenle Karakuş ve Yasan'ın (2013) dediği gibi gelişmiş ülkeler eğitim sistemlerinde stratejik

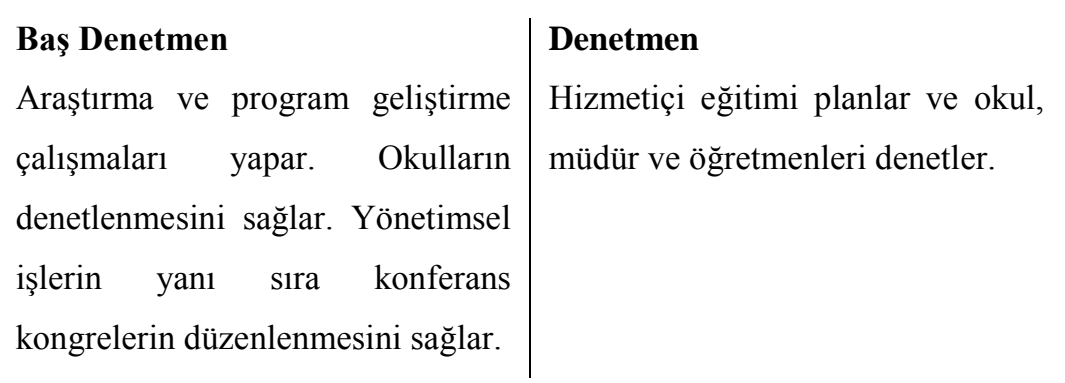

\section{Baş Denetmen}

Araştırma ve program geliştirme denetlenmesini sağlar. Yönetimse kongrelerin düzenlenmesini sağlar. 
planlamalar yapmakta ve eğitimde sürekli olarak reformlar gerçekleştirmektedir. Gelişmiş ülkelerin temelinde eğitim sistemi üç öğe üzerinde dönmektedir. Bunlar öğretim, yönetim ve denetim olarak sıralanabilir.

Aydın'a (2007), göre denetim, örgütsel eylemlerin kabul edilen amaçlar doğrultusunda, saptanan ilke ve kurallara uygun olup olmadığının anlaşılması sürecidir. Denetimin özüne bakıldığı zaman denetim aslında verimliliği artırma ve işgörenin gelişimi için büyük önem taşımaktadır. Denetim eğitim sisteminin bir alt sistemi olup durum saptama, değerlendirme, düzeltme ve geliştirme öğelerinin bir araya geldiği çok yönlü ve kapsamlı bir süreçtir (Gökyer, 2009). Bu sürecin işleyişi ve düzün bir biçimde uygulanması günümüzde Eğitim Bakanlıklarına bağlı denetmenler tarafından sağlanmaktadır. Araştırma kapsamında her iki toplumun yasa ve tüzükleri doğrultusunda yapılan incelemelerde denetmen görev ve sorumlulukları benzerlik göstermektedir. Her iki tolpumunda eğitim sistemi merkezi yapıya sahiptir. Denetmenlerin görev, sorumluluk ve atamaları bakanlık aracılığı ile yapılmaktadır.

Denetmenlerin okulu veya öğretmenleri denetleyebilmeleri için, yönetici ve öğretmenlerden daha üstün bir bilgi birikimi ve eğitim düzeyine sahip olmaları gerektiğini savununa pek çok araştırma bulunmaktadır. Yapılan bu araştırmalarda; denetmenlerin, öğretmen altyapısından gelmesi, eğitim yönetimi programından mezun olmaları ve sınavla seçilmeleri, bunun akabinde ataması gerçekleştitilecek olan yöneticilerin göreve başlamadan eğitim görmeleri, atanacakları kurumda öncellikle çalışıp sonrasında üst kademe yöneticiliğe yükselmelerinin sağlanması (Günay, 2004); eğitim yöneticiliğinin geleceği bakımından yöneticilerin eğitim yönetimi alanında doktora eğitimi alıp, bilgi ve becerilerinin gelişmesinin önemli bir faktör olduğu (Dinçer, 2008); denetleyen kişinin, denetelenenden daha fazla eğitim ve bilgiye sahip olması gerektiği (Yıldırım ve Koçak, 1994); denetmenlerin kendini geliştirmek için sürekli hizmetiçi eğitim uygulamalarından geçmeleri gerektiği (Can, 2004); eğitim denetmenlerinin sahip olacağı nitelik ve yeterliliklerinin olabildiğince fazla olması gerektiği (Taymaz, 2011); ders denetimi yapacak kişilerin bu alanlarda yurt dişında olduğu gibi yüksek lisans ve doktora eğitiminden geçmelerinin gerektiği (Dağl1, 2006) gibi bulgulara rastlanmaktadir.

\section{Sonuç}

İki topluma ait yasa ve tüzükler incelendiğinde denetmen görev ve sorumluluklarında farklılık öne çıkmaktadır. Kuzey Kıbrıs'ta denetmen görev ve yetkileri çoğunluklu olarak eğitim sistemini ve öğretmeni denetlemeye yönelik iken Güney Kıbrıs’ta rehber olma daha ön plana 
çıksada yeterli değildir. Literatürde yapılan birçok araştırmada denetimde rehberliğin önemi üzerinde durulmuştur (Cottrell ve diğerleri, 2002; Jahanian ve Ebrahimi, 2013). Her iki toplumun yasa ve tüzükleri incelendiğinde dentmenin rehber olma ve yönlendirme gibi görev tanımının yapılmadığı görülmektedir.

Eğitim denetimi, günümüzde özel bir uzmanlık alanı olarak karşımıza çıkmaktadır. Taymaz (2011) yaptı̆̆ı araştırmada denetmenin görev ve sorumluluklarının, kurumlarda çalışan personelin görevlerini yapma şekillerini gözlemek, hataları ve eksikleri ortaya koymak, bunları düzeltmeleri için gerekli önlemleri almak, sorunları çözümlemek, yenilikleri tanıtmak, yöntemleri geliştirilmesini sağlamak olduğunu vurgulamaktadır. Fakat her iki toplumda da denetmen görev ve sorumluluklarının fazla olması ve kısıtlı zamanları olmasından ötürü verimli ve etkili çalışmaları bu bakımdan yeterli olmayabilir. Yasa ve tüzüklerin gerekliliği olan bürokratik uygulamalar ve iş yükünün fazlalığı dolayısıyla günümüzde denetmenden beklenen rehber ve yönlendirici olma ile performans değerlendirme sürecinde etkili olmaları beklenemez.

\section{Kaynaklar}

Aydın, M. (2007). Çağdaş eğitim denetimi. (5. baskı ). Ankara: Hatipoğlu

Başar, H. (2006).Türkiye'de eğitim denetimi. Hesapçığlu, M. ve Durmuş A. (Ed.), Türkiye'de Eğitim Bilimleri: Bir Bilanço Denemesi. Ankara: Nobel Yayın Dağıtım.

Can, N. (2004). İlköğretim Öğretmenlerinin Denetim ve Sorunları. Milli Eğitim Dergisi, 161, 112-120

Cottrell, D., Kilminster, S., Jolly, B. \& Grant, J. 2002. What is effective supervision and how does it happen? A critical incident study. Medical Education, 36(11), 1042-1049.

Dağlı, A. (2006). İlköğretim denetmenlerinin eğitim ve yaşam ile ilgili karşılaştıkları sorunlar ve bu sorunların çözümüne ilişkin öneriler. D.Ü. Ziya Gökalp Eğitim Fakültesi Dergisi, 6, 1-8.

Dinçer, Y. (2008). Eğitim Kurumlarına Yönetici Seçme ve Atamaya ilişskin Okul Yöneticilerinin Görüşlerinin Değerlendirilmesi, Yayınlanmamış Yüksek Lisans Tezi, Yeditepe Üniversitesi, Sosyal Bilimler Enstitüsü, İstanbul.

Eurydice. (2007). Avrupa'daki eğitim sistemleri. Erişim tarihi:01.10.2017. URL : www.eurydice.org/ Eurybase/ Application frameset.asp?Country $=$ SW \&language $=\mathrm{EN}$

Eurydice/Cedefob. (2003). Structuresofeducation, vocationaltrainingandadulteducationsystems in Europa, Cyprus 2004. Erişim tarihi: 01.10.2017. http://www.Eurydice.org/ portal/page/portal/Eurydice/ ByCountryResults?countryCode $=$ AT \&regionCode $=$ null.

Eurydice/Eurybase. (2002). Theinformationdatabase on educationsystems Europe. Erişim tarihi: :01.10.2017. http://www.Eurydice.org/ portal/page/portal/Eurydice/ DB_Eurybase_Home

Günay, E. (2004). Eğitim Kurumlarına Yönetici Seçme, Yetiştirme ve Atamaya İlişsin Yönetici ve Öğretmen Görüşlerinin Değerlendirilmesi, Yayınlanmamış Yüksek Lisans Tezi, Ankara Üniversitesi, Eğitim Bilimleri Enstitüsü, Ankara. 
Gündüz, Y., ve Balyer, A. (2012). Türkiye'de ve bazı Avrupa ülkelerinde müfettişlerin yetiştirilme süreci ve karşılaşılan sorunlar. Mersin Üniversitesi Ĕ̆itim Fakültesi Dergisi, 8(1), 84-95.

Jahanian, R. \& Ebrahimi, M. (2013). Principles for educational supervision and guidance, Journal of Sociological Research, 4(2), 380-390.

Karakuş, M. Ve Yasan, T. (2013). Denetmen ve öğretmen algılarına göre il eğitim denetmenlerinin yeterlilikleri. Dicle Üniversitesi Ziya Gökalp Eğitim Fakültesi Dergisi, 21,1-9.

Karasar, N. (2007) Bilimsel Araştırma Yöntemleri, Ankara: Nobel yayınları

Kuzey Kıbrıs Milli eğitim denetleme, değerlendirme ve yönlendirme kurulu yasası. (2006). Kuzey Kıbrıs Resmi Gazete, 76, 2 Mayıs 2006.

Sergiovanni, T.J. ve Starrat, R.J. (2002). Supervision: A Redefinion (Seventh Ed.), New York: McGrawHillHigherEducation.

Taymaz, H. (2011). Ĕgitim sisteminde teftiş, kavramlar, ilkeler, yöntemler. Ankara: Pegem Akademi.

Terzi, A. R. (1996). İlköğretim müfettişlerinin teftiş sorunları (Ankara İli Örneği), Yayınlanmamış Yüksek Lisans Tezi, Gazi Üniversitesi, Ankara.

Yıldırım, İ., \& Koçak, Ş. (1994). Ĕ̌gitim Denetiminde İlköğretim Müfettişleri Yetiştirilme ve Sorunları. Yayınlanmamış araştırma, Dicle Üniversitesi, Diyarbakır.

Yıldırım, A., ve Şimşek, H. (2006). Sosyal Bilimlerde Nitel Araştırma Yöntemleri. (6. baskı) Ankara: Seçkin Yayıncilik. 